\title{
Структура и электрические свойства пленок на основе оксида олова, легированных цирконием
}

\author{
(C) А.В. Ситников, О.В. Жилова , И.В. Бабкина, В.А. Макагонов, Ю.Е. Калинин, О.И. Ремизова \\ Воронежский государственный технический университет, \\ 394026 Воронеж, Россия \\ "E-mail: zhilova105@mail.ru
}

(Получена 21 декабря 2017 г. Принята к печати 5 февраля 2018 г.)

\begin{abstract}
Тонкие пленки $\mathrm{SnO}_{2}$, стабилизированные $\mathrm{Zr}$, были получены ионно-лучевым реактивным распылением. В одном технологическом процессе были синтезированы аморфные тонкопленочные образцы $\mathrm{SnO}_{2}$ с различной концентрацией $\mathrm{Zr}$. Исследовано влияние термической обработки на структуру и электрические свойства синтезированных пленок. В тонкопленочных системах $\mathrm{Sn}-\mathrm{Zr}-\mathrm{O}$ начало процесса кристаллизации наблюдается при температурах 673 и $773 \mathrm{~K}$, что сопровождается появлением метастабильных фаз. При нагреве до $873 \mathrm{~K}$ эти фазы преобразуются в $\mathrm{Sn}+\mathrm{Sn}_{2} \mathrm{O}_{3}$.

Было обнаружено,что после кристаллизации пленок процесс электропереноса при температурах, близких к комнатной, является термоактивационным с энергией активации $\sim 0.78$ эВ. Пленки оксида олова, легированные $\mathrm{Zr}$ от 0.6 до 3.9 ат\%, после кристаллизации проявляют свойства газовой чувствительности к водороду.
\end{abstract}

DOI: $10.21883 /$ FTP.2018.09.46146.8804

\section{1. Введение}

Оксид олова, являясь широкозонным полупроводником, обладает интересным сочетанием свойств: прозрачностью в видимом диапазоне электромагнитного излучения, большим электрическим сопротивлением и высокой газовой чувствительностью. Такие свойства обеспечивают $\mathrm{SnO}_{2}$ широкое практическое применение в качестве солнечных элементов, газовых сенсоров и других устройств электронной техники [1-3]. Несмотря на сходство с другими широкозонными полупроводниками, оксид олова имеет ряд особенностей. Во многих случаях можно считать, что кристаллическая решетка оксида олова состоит из катионов металла и анионов кислорода, в результате чего такие дефекты, как вакансии и межузельные атомы, являются заряженными и электрически активными, т.е. могут проявлять донорные или акцепторные свойства. Однако нелегированный $\mathrm{SnO}_{2}$ обладает только электронным типом проводимости [4].

Несмотря на большое внимание со стороны физиков и материаловедов к исследованию оксида олова, природа многих экспериментально наблюдаемых особенностей электрофизических свойств остается до конца не ясной $[5,6]$. Так, газовая чувствительность тонких пленок оксида олова определяется процессами на поверхности зерен, влияющих на ее электрическую проводимость [7]. Оксид олова имеет высокое электрическое сопротивление и большую ширину запрещенной зоны $\sim 3.5$ эВ, поэтому при повышенных температурах $(\sim 673 \mathrm{~K})$ почти не происходит увеличение собственной проводимости полупроводника [8-10].

Для уменьшения электрического сопротивления используют поликристаллический оксид олова с нанометровым размером зерен, у которого электропроводность повышается из-за большого числа дефектов в зернограничном слое. Но при этом возникает несколько проблем. Во-первых, нужно стабилизировать мелкодисперсную кристаллическую структуру, так как при высоких температурах начинается процесс рекристаллизации. Во-вторых, наличие легирующих добавок изменяет энергетические состояния носителей заряда $[11,12]$. Bce это влияет на механизмы изменения плотности поверхностных зарядов при адсорбции атомов и молекул различных газов.

Для решения данных проблем обычно используют тонкопленочные образцы, что позволяет повысить вклад поверхностных состояний в электротранспортные свойства полупроводника.

Одним из способов получения нанокристаллических пленок $\mathrm{SnO}_{2}$ является управляемая кристаллизация из аморфного состояния, для формирования которой используют аморфизирующие элементы тугоплавких металлов. Последние в процессе термической обработки аморфной структуры замедляют процесс кристаллизации и стабилизируют нанокристаллическую структуру, что и влияет на поверхностные энергетические состояния носителей заряда на границе раздела между кристаллитами.

В данной работе в качестве аморфизирующей добавки был выбран цирконий $(\mathrm{Zr})$. Это обусловлено следующими причинами: цирконий - элемент, используемый для образования аморфной структуры широкого класса сплавов; Zr может являться катализатором при взаимодействии водорода с $\mathrm{SnO}_{2} ; \mathrm{ZrO}_{2}$ имеет высокую температуру плавления, поэтому препятствует увеличению размеров зерен в процессе кристаллизации и рекристаллизации структуры при термической обработке.

Таким образом, использование $\mathrm{Zr}$ в качестве легирующего элемента в соединении $\mathrm{SnO}_{2}$ позволит выявить влияние различных факторов на электрические и сенсорные свойства оксида олова. 


\section{2. Образцы и методика эксперимента}

Тонкие пленки $\mathrm{SnO}_{2}$, стабилизированные $\mathrm{Zr}$, были получены методом ионно-лучевого реактивного распыления [13]. Для формирования тонкопленочной структуры оксида олова с различной концентрацией циркония использовалась составная мишень, которая представляла собой литую основу олова размером $280 \times 80$ мм, на поверхности которой закрепляли пять пластин из циркония размером $80 \times 9 \times 2$ мм. Расстояние между пластинами циркония плавно изменялось от 5 мм на одном краю мишени до 45 мм на другом, что позволило в одном технологическом цикле получить различные соотношения концентрации $\mathrm{Zr}$ в зависимости от положения подложки относительно мишени.

В качестве основного рабочего газа использовался аргон (Ar) чистотой $99.992 \%$. Во время технологического процесса рабочий газ непрерывно подавался в камеру. Перед напылением рабочую камеру откачивали до давления не хуже $1 \cdot 10^{-5}$ Торр. В качестве реактивного газа использовался кислород. Выбор парциального давления кислорода относительно $\mathrm{Ar}$ позволил получить пленки олова в окисленном состоянии и регулировать величину удельного электрического сопротивления пленок.

Первой технологической операцией осаждения пленки является спыливание поверхности мишени в течение 30 мин. Затем проводилась ионная очистка подложки для улучшения адгезионных свойств. Потом в течение нескольких минут осаждалась пленка $\mathrm{SnO}_{2}$, легированная $\mathrm{Zr}$, до достижения необходимой толщины.

В качестве подложек использовались пластины ситалла СТ-50-0.6. Состав пленок определялся электроннозондовым рентгеновским микроанализом по пяти измерениям, взятым с различных участков подложек, c последующей полиномной экстраполяцией состава по длине подложки. Образцы, полученные в результате напыления, представляли собой пленки толщиной 0.15-1.5 мкм. Толщина пленок измерялась на интерферометре МИИ-4. Для анализа фазового состава полученных пленок были проведены рентгеноструктурные исследования на рентгеновском дифрактометре Bruker D2 Phaser. Обработка результатов осуществлялась программными средствами Bruker DIFFRAC EVA3.0 с применение базы данных PDF2012 и TOPAS 4.2. При измерении температурной зависимости электрического сопротивления использовались напыленные на ситалловую подложку образцы длиной 9 мм.

Измерения удельного электрического сопротивления проводили с использованием 2-зондового потенциометрического метода. Абсолютная погрешность измерения температуры составляла $\pm 1 \mathrm{~K}$, а относительная погрешность измерения электрического сопротивления $-0.5 \%$.

\section{3. Экспериментальные результаты}

\section{1. Структура синтезированных пленок}

Структура пленок $\mathrm{Sn}-\mathrm{Zr}-\mathrm{O}$ была исследована в работе [12]. Показано, что в исходном состоянии пленка

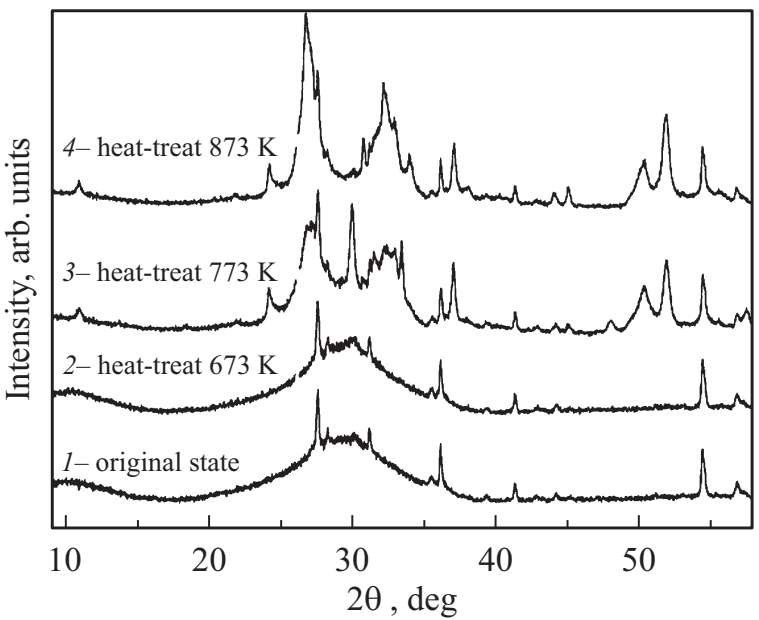

Pис. 1. Дифрактограммы пленок $\mathrm{Sn}-\mathrm{Zr}-\mathrm{O}(\mathrm{Zr}=3.9 \mathrm{aT} \%)$ в исходном состоянии (кривая 1) и после термообработки в течение 30 мин при температурах 673 (кривая 2), 773 (кривая 3) и $873 \mathrm{~K}$ (кривая 4).

имеет аморфную структуру. После термической обработки при температуре $773 \mathrm{~K}$ в течение 17 ч происходит кристаллизация аморфной пленки. Размер кристаллитов зависит от концентрации циркония. При увеличении содержания $\mathrm{Zr}$ от 0.5 до $4.6 \mathrm{aT} \%$ размер кристаллитов уменьшается от 40 до 10 нм.

В отличие от [12], где термическая обработка осуществлялась в воздушной среде, в данной работе термический отжиг пленок проводился в вакуумной камере при остаточном давлении не хуже $10^{-5}$ Торр. Это позволило сопоставить полученные структурные превращения с исследованными температурными зависимостями удельного электрического сопротивления $\rho(T)$. Анализ дифрактограмм синтезированных пленок показал, что до температур $673 \mathrm{~K}$ образец сохраняет аморфную структуру (кривые 1,2 на рис. 1). Наблюдаемые на зависимостях максимумы принадлежат материалу подложки СТ50-0.6. Кристаллизация аморфной пленки происходит после термической обработки при $773 \mathrm{~K}$ в течение 30 мин с выделением кристаллитов $\mathrm{SnO}$ тетрагональной структуры пространственной группы симметрии P4/nmm (pdf 01-072-1012) и $\mathrm{Sn}_{2} \mathrm{O}_{3}$ триклинной структуры пространственной группы симметрии Р-1 (pdf 00-025-1259) (кривая 3 на рис. 1). Повышение температуры обработки (873 K в течение 30 мин) приводит к выделению металлического олова тетрагональной структуры пространственной группы симметрии I41/amd (pdf 01-089-4898) и исчезновению фазы SnO (кривая 4 на рис. 1). Цепочку обнаруженных превращений можно записать как

$\begin{aligned} & \text { исходная аморфная } \\ & \text { структура }\end{aligned} \stackrel{400 \mathrm{~K}}{\longrightarrow} \begin{aligned} & \text { аморфная } \\ & \text { структура }\end{aligned} \stackrel{500 \mathrm{~K}}{\longrightarrow} \mathrm{SnO}+\mathrm{Sn}_{2} \mathrm{O}_{3}$ $\stackrel{600 \mathrm{~K}}{\longrightarrow} \mathrm{Sn}+\mathrm{Sn}_{2} \mathrm{O}_{3}$ 


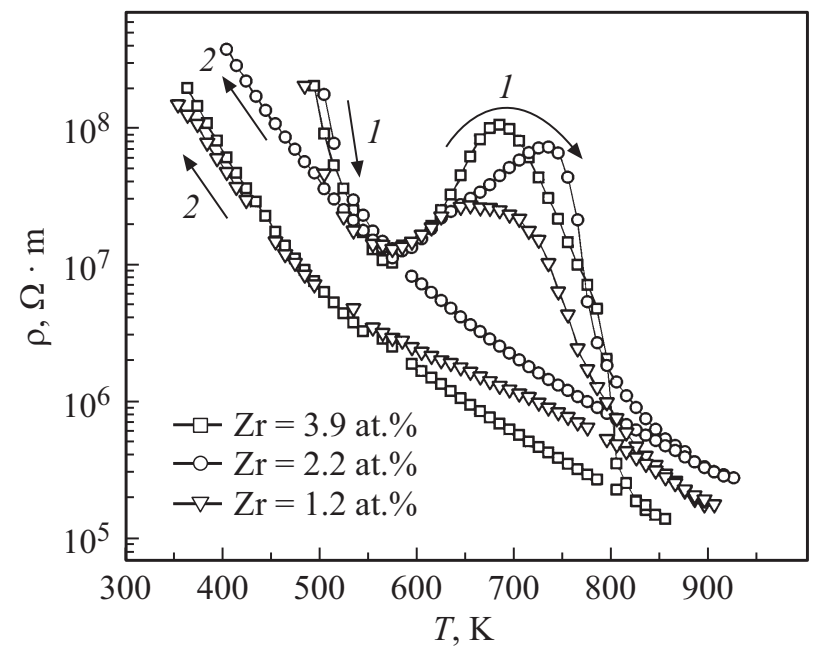

Рис. 2. Температурные зависимости удельного электрического сопротивления пленок при нагреве (кривая 1) и охлаждении (кривая 2) в атмосфере аргона при $P=380$ Торр с различным содержанием циркония.

\section{2. Электрические свойства синтезированных пленок}

Описанные выше структурные превращения пленок $\mathrm{Sn}-\mathrm{Zr}-\mathrm{O}$ должны отражаться на процессах электропереноса. В связи с этим были исследованы температурные зависимости удельного электрического сопротивления пленок оксида олова с различным содержанием примесных атомов (Zr) (рис. 2).

Анализ полученных зависимостей показал, что в области температур 573-773 K наблюдается максимум $\left(\rho_{\max } \sim 673 \mathrm{~K}\right)$. Надо заметить, что степень изменения электрического сопротивления $\Delta \rho$ повышается с увеличением концентрации циркония в пленке. После прохождения максимальных значений $\rho$ электрическое сопротивление быстро понижается вплоть до температур окончания термического воздействия $(873 \mathrm{~K})$. При охлаждении образца кривые $\rho(T)$ монотонны и аппроксимируются экспоненциальной зависимостью $\rho \sim \exp (1 / T)$, что характерно для полупроводниковых материалов.

Наличие максимума на зависимости $\rho(T)$ при нагреве пленки можно объяснить, если учитывать экспериментальные данные исследования структуры после термической обработки:

— в температурном интервале от 573 до 673 К структура пленки остается аморфной;

- термообработка при $773 \mathrm{~K}$ в течение 30 мин приводит к кристаллизации пленки с выделением кристаллитов $\mathrm{Sn}_{2} \mathrm{O}_{3}$ и $\mathrm{SnO}$;

- повышение температуры отжига $(873 \mathrm{~K}$ в течение 30 мин) преобразует кристаллы $\mathrm{SnO}$ в оксид $\mathrm{Sn}_{2} \mathrm{O}_{3}$ и $\mathrm{Sn}$;

- фазы с Zr, значительной для рентгеновской идентификации, не выявлено.

Можно предположить, что в пределах аморфной структуры пленки в температурном диапазоне от 573 до $673 \mathrm{~K}$ происходят изменения в ближнем порядке атомов, приводящие к увеличению электрического сопротивления образцов. Данный процесс может быть связан с протеканием процессов структурной релаксации аморфной структуры в исследуемых пленках. Понижение электрического сопротивления на зависимости $\rho(T)$ выше $673 \mathrm{~K}$ связано с процессами кристаллизации. Недостаток кислорода при синтезе пленки реактивным способом из металлической мишени приводит к формированию фаз непредельного оксида олова $\mathrm{Sn}_{2} \mathrm{O}_{3}$ и $\mathrm{SnO}$. Повышение степени окисления металлических атомов $\mathrm{Snc}$ $\mathrm{SnO}$ до $\mathrm{Sn}_{2} \mathrm{O}_{3}$ и образования кристаллов металлической фазы уменышает скорость изменения $\rho(T)$.

При охлаждении образца, нагретого до температуры $873 \mathrm{~K}$, кривые $\rho(1 / T)$ аппроксимируются экспоненциальной зависимостью. Если температурную зависимость электрического сопротивления исследованных композитов описать уравнением Аррениуса [14]:

$$
\rho=\rho_{0} \cdot \exp \left(-\frac{E_{a}^{R}}{2 k T}\right),
$$

где $E_{a}^{R}-$ энергия активации электрической проводимости; $k-$ постоянная Больцмана; $T-$ абсолютная температура, то по экспериментальным зависимостям (рис. 3) можно определить значения энергии активации проводимости $E_{a}^{R}$, которые для пленок $\mathrm{Sn}-\mathrm{Zr}-\mathrm{O}$ с различным содержанием Zr представлены в таблице.

Анализ рассчитанных значений энергии активации показал, что $E_{a}^{R}$ составляет $\sim 0.78 \pm 0.05$ эВ и практически не изменяется с изменением концентрации циркония. Полученное значение энергии активации можно связать с донорным уровнем в запрещенной зоне оксида олова, создаваемого примесными атомами циркония, создающими в кристаллической решетке дефекты замещения.

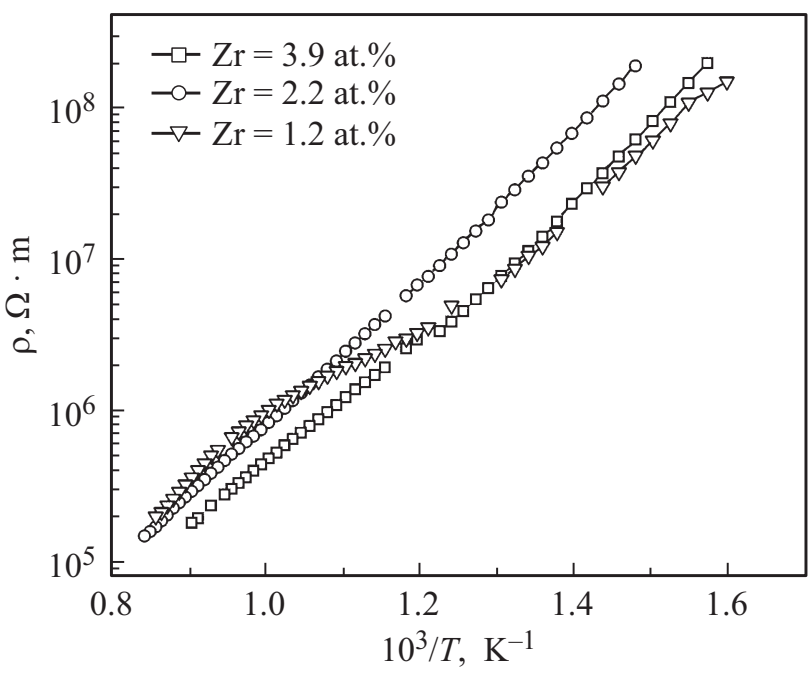

Рис. 3. Температурные зависимости удельного электрического сопротивления пленок, полученные при охлаждении в атмосфере аргона при $P=380$ Торр с различным содержанием циркония в координатах $\ln (\rho)=f(1 / T)$. 
Энергия активации процесса проводимости пленок $\mathrm{Sn}-\mathrm{Zr}-\mathrm{O}$ в зависимости от содержания $\mathrm{Zr}$ после нагрева образцов до $600 \mathrm{~K}$

\begin{tabular}{c|c}
\hline $\begin{array}{c}\text { Концентрация } \mathrm{Zr} \\
(\text { ат\%) }\end{array}$ & $\begin{array}{c}\text { Энергия } \\
\text { активации }(э \mathrm{~B})\end{array}$ \\
\hline 3.9 & $0.78 \pm 0.05$ \\
2.2 & $0.83 \pm 0.05$ \\
1.2 & $0.73 \pm 0.05$
\end{tabular}

\section{3. Влияние водорода на электрические свойства пленок $\mathrm{Sn}-0$, легированных $\mathrm{Zr}$}

Рассмотренные структурные и фазовые превращения при термической обработке тонкопленочного оксида олова, легированного $\mathrm{Zr}$, а также связанные с ними изменения электрических свойств должны оказывать влияние на процессы образования поверхностных состояний в широкозонном полупроводнике при адсорбции атомов различных газов [12]. В работе были проведены измерения относительного изменения электрического сопротивления исследуемых пленок в атмосфере аргона и при добавлении водорода. Измерения проводились на образцах, предварительно подвергнутых термообработке при температуре $873 \mathrm{~K}$ в течение 30 мин.

В работе были также проведены исследования влияния поверхностного катализатора на газовую чувствительность пленок. Поверхностная модификация пленки $\mathrm{Sn}-\mathrm{Zr}-\mathrm{O}_{2}$ примесями катализаторов осуществлялась под микроскопом нанесением микрокапли водного раствора известной концентрации солей хлорида палладия $\left(\mathrm{PdCl}_{2}\right)$ на поверхность пленки. Водный раствор имел $5 \%$ палладия. После нанесения капля водного раствора высушивалась при комнатной температуре, затем образцы подвергались нагреву в течение 30 мин при $773 \mathrm{~K}$.

На рис. 4 представлены результаты исследований пленок $\mathrm{Sn}-\mathrm{Zr}-\mathrm{O}$ с содержанием $2.2 \mathrm{aT} \% \mathrm{Zr}$ в среде $\mathrm{Ar}$ и при добавлении в инертную среду 7.6 Торр водорода. Временны́е зависимости $\Delta R / R \cdot 100 \%$, рассчитывались по уравнению

$$
\frac{\Delta R}{R}=\frac{R-R_{0}}{R_{0}} 100 \%,
$$

где $R_{0}$ - электрическое сопротивление образца при начальном давлении или концентрации газа, $R$ - электрическое сопротивление образца во время измерения при $T=623 \mathrm{~K}$.

Кривые на рис. 4, $b$ соответствуют пленке с предварительно нанесенным на поверхность Рd. Видно, что присутствие катализатора не влияет на величину газовой чувствительности.

При увеличении концентрации $\mathrm{Zr}$ палладий уменьшает величину $\Delta R / R \cdot 100 \%$. Это возможно, если предположить, что $\mathrm{Zr}$ выступает в данных пленках в качестве катализатора адсорбционных процессов.

Наибольшее влияние на газовую чувствительность пленок $\mathrm{Zr}$ оказывает при его концентрации $\sim 1.2 \mathrm{aT} \%$.
Возможно, это связано с образованием твердого раствоpa $\mathrm{Zr}$ в $\mathrm{SnO}_{2}$ без выделения отдельной фазы.

При нагреве от 473 до $623 \mathrm{~K}$ относительное изменение электрического сопротивления пленок системы $\mathrm{Sn}-\mathrm{O}$ с добавлением $\mathrm{Zr}$ 0.6-3.9 ат\% увеличивается.

Надо заметить, что использование водорода в качестве пробного газа в пленках $\mathrm{Sn}-\mathrm{Zr}-\mathrm{O}$, находящихся в воздушной среде, вызывает более существенное изменение, чем в образцах, помещенных в инертную среду. Газовая чувствительность сенсоров на основе оксида олова определяется процессами на поверхности зерен, составляющих пленку и влияющих на ее электрическую проводимость. Основными из них являются изменение концентрации вакансий кислорода в объеме за счет обмена с поверхностью, адсорбция частиц из газовой фазы, индуцирующих донорные или акцепторные уровни, протекание химических реакций на поверхности зерен, приводящих к изменению заполнения центров адсорбции [8].

Для объяснения изменений электропроводности тонкой пленки окиси олова, содержащей цирконий, при

$a$
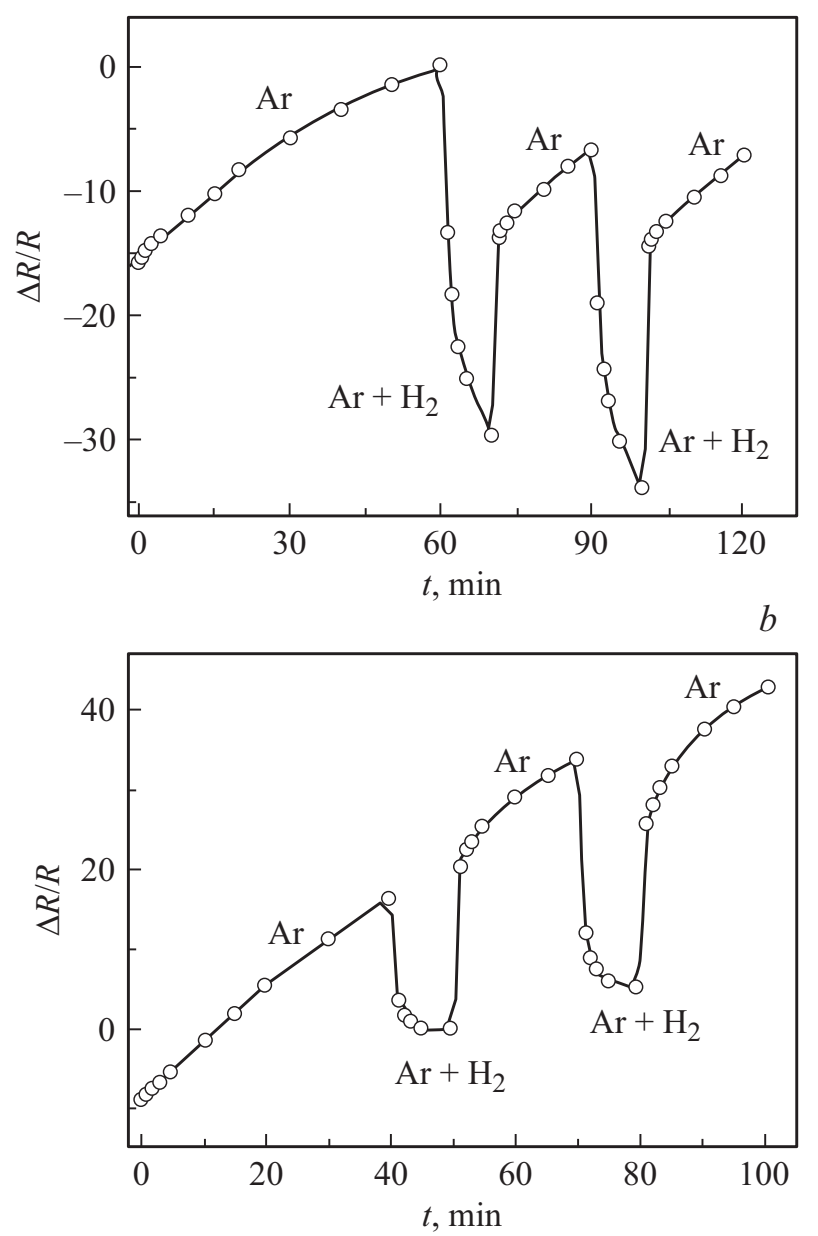

Рис. 4. Временны́е зависимости относительного изменения электрического сопротивления пленок системы $\mathrm{Sn}-\mathrm{Zr}-\mathrm{O}$ с содержанием $\mathrm{Zr} 2.2$ ат\% при $T=350 \mathrm{~K}$ : без покрытия $(a)$ и с $\mathrm{Pd}$, нанесенным на поверхность $(b)$. 
контакте с газовой средой различного состава привлекается электронная теория хемосорбции и катализа, основанная на поверхностных электронных состояниях полупроводников [15]. Адсорбированные на поверхности оксида молекулы газа могут либо отдавать электроны (доноры), либо присоединять к себе электроны из оксида (акцепторы). Оксид олова, легированный цирконием, является полупроводником $n$-типа, и адсорбция молекул акцептора приводит к созданию приповерхностных областей, обедненных электронами, что вызывает уменьшение электропроводности. Так, например, действует аргон и воздух, что наблюдалось при экспозиции пленки $\mathrm{Sn}-\mathrm{Zr}-\mathrm{O}$ в среде аргона (участки роста на рис. 4). При адсорбции молекул донорного типа на оксиде $n$-типа создается поверхностный слой, обогащенный электронами, что увеличивает электропроводность. Этот случай реализуется при адсорбции водорода (участки спада на рис. 4).

Таким образом, в системах $\mathrm{Zr}-\mathrm{Sn}-\mathrm{O}$ цирконий не изменяет тип проводимости оксида олова и выступает в качестве катализатора процессов адсорбции молекулярного водорода, что может быть связано с наличием твердого раствора циркония в оксиде олова.

\section{4. Заключение}

Методом ионно-лучевого реактивного распыления синтезированы тонкие аморфные пленки оксида олова, допированные цирконием с концентрацией от 0.6 до $3.9 \mathrm{aT} \%$. При нагреве тонкопленочных систем $\mathrm{Zr}-\mathrm{Sn}-\mathrm{O}$ начало процесса кристаллизации наблюдается при температурах 673 и $773 \mathrm{~K}$, сопровождаясь выделением метастабильных фаз $\mathrm{SnO}+$ аморфная фаза и $\mathrm{SnO}+\mathrm{Sn}_{2} \mathrm{O}_{3}$, которые претерпевают существенные изменения при дальнейшем нагреве до $600 \mathrm{~K}$, превращаясь в $\mathrm{SnO}+\mathrm{Sn}_{2} \mathrm{O}_{3}$

Такое поведение может быть связано с тем, что $\mathrm{Zr}$ образует твердые растворы с оксидом олова, которые не оказывают сильного воздействия на температуру кристаллизации, но способствуют образованию фаз с непредельными модификациями оксидов олова.

Установлено, что после кристаллизации пленок оксида олова, легированного $\mathrm{Zr}$, процесс электропереноса при температурах, близких к комнатной, является термоактивационным с энергией активации $\sim 0.78$ эВ. Для пленок $\mathrm{Zr}-\mathrm{Sn}-\mathrm{O}$ значения $E_{a}^{R}$ можно связать с донорными уровнями, образованными растворенными атомами $\mathrm{Zr}$.

Пленки оксида олова с добавлением $\mathrm{Zr}$ от 0.6 до 3.9 ат\% после кристаллизации проявляют газосенсорные свойства по отношению к водороду. В системах $\mathrm{Zr}-\mathrm{Sn}-\mathrm{O}$ цирконий выступает в качестве катализатора процессов адсорбции молекулярного водорода, что может быть связано с наличием твердого раствора циркония в оксиде олова.

Работа выполнена при поддержке Министерства образования и науки в рамках проектной части государственного задания (проект № 3.1867.2017/4.6).

\section{Список литературы}

[1] A. Goetzberger, C. Hebling. Sol. Energy Mater. Sol. Cells, 62, 1 (2000).

[2] P. Nelli, G. Faglia, G. Sverbeglieri, E. Cereda, G. Garbetta, A. Dieguez, A.R. Rodriguez, J.R. Morante. Thin Sol. Films, 371, 249 (2000).

[3] Л.С. Паршина, О.Д. Храмова, О.А. Новодворский, А.А. Лотин, И.А. Петухов, Ф.Н. Путилин, К.Д. Щербачев. ФТП, 51, 426 (2017).

[4] К.П. Богданов, Д.Ц. Димитров, О.Ф. Луцкая, Ю.М. Таиров. ФТП, 32, 1158 (1998).

[5] S. Monredon, A. Cellot, F. Ribot, C. Sanchez, L. Armelao, L. Gueneau, L. Delattre. J. Mater. Chem., 12, 2396 (2002).

[6] N.-S. Baik, G. Sakai, N. Miura, N. Yamazoe. J. Am. Ceram., 83 (12), 2983 (2000).

[7] О.С. Махди, И.В. Маля, И.В. Синѐв, С.Б. Вениг, В.В. Кисин. Материалы Всероссийской научной школы-семинара (Саратов, Россия, 2016) с. 34.

[8] H.-W. Ha, K. Kim, M. de Borniol, T. Toupance. J. Solid State Chem., 179, 702 (2006).

[9] E.S. Rembeza, O. Richard, J.V. Landuyt. Mater. Res. Bulletin, 34, 1527 (1999).

[10] J. Rockenberger, U. zum Felde, M. Tischer, L. Troger, M. Haase, H. Weller. J. Chem. Phys., 112, 4296 (2000).

[11] N. Sergent, P. Gelin, L.P. Camby, H. Praliaud, G. Thomas. Sensors Actuators B, 84, 176 (2002).

[12] С.И. Рембеза, Е.С. Рембеза, Т.В. Свистова, Н.Н. Кошелева, В.М.К. Аль Тамееми. ФТП, 49 (9), 1273 (2015).

[13] С.А. Гриднев, Ю.Е. Калинин, А.В. Ситников, О.В. Стогней. Нелинейные явления в нано- и микрогетерогенных системах (М., БИНОМ, Лаб. знаний, 2012).

[14] Г. Буш. УФН, 6, 258 (1952).

[15] А.М. Гаськов, М.Н. Румянцева. Неорг. матер., 36, 369 (2000).

Редактор Г.А. Оганесян

\section{The structure and electrical properties of ziconium-doped tin oxide films}

\author{
A.V. Sitnikov, O.V. Zhilova, I.V. Babkina, \\ V.A. Makagonov, Yu.E. Kalinin, O.I. Remizova
}

Voronezh State Technical University, 394026 Voronezh, Russia

\begin{abstract}
Thin films of $\mathrm{SnO}_{2}$ stabilized by $\mathrm{Zr}$ were obtained by ion-beam reactive sputtering. In one technological process, amorphous thin-film $\mathrm{SnO}_{2}$ samples with various $\mathrm{Zr}$ concentrations were synthesized. The effect of heat treatment on the structure and electrical properties of synthesized films was studied. In thinfilm $\mathrm{Zr}-\mathrm{Sn}-\mathrm{O}$ systems, the onset of the crystallization process is observed at temperatures of 673 and $773 \mathrm{~K}$, which is accompanied by the appearance of metastable phases. When heated to $873 \mathrm{~K}$, these phases are converted into $\mathrm{Sn}+\mathrm{Sn}_{2} \mathrm{O}_{3}$. It was found that after the crystallization films the electrotransfer process at temperatures close to room is an thermoactivation with activation energy $\sim 0.78 \mathrm{eV}$. Films of tin oxide the doped of $\mathrm{Zr}$ from 0.6 to 3.9 at $\%$ after crystallization show gas sensitivity properties on hydrogen.
\end{abstract}

